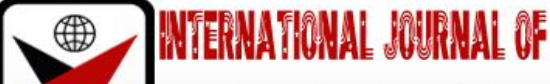

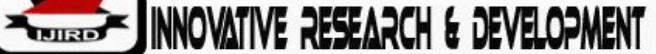

ISSN 2278 - 0211 (Online)

\section{The Impact of Pre-National Diploma Programme on Academic Performance: A Case Study of Selected Polytechnics in Northeast Nigeria}

\author{
Maigana Alhaji Bakawu \\ Lecturer, Department of Statistics, Mai Idris Alooma Polytechnic Geidam, Yobe State, Nigeria \\ Abdulrahman Malik \\ Lecturer, Department of Statistics, Mai Idris Alooma Polytechnic Geidam, Yobe State, Nigeria \\ Auwalu Chiroma \\ Lecturer, Department of Statistics, Mai Idris Alooma Polytechnic Geidam, Yobe State, Nigeria
}

\begin{abstract}
:
This paper examined the academic performance of students admitted into National Diploma (ND) programme through PreNational Diploma (Pre- ND) programme and Unified Tertiary Matriculation Examination (UTME) in some selected polytechnics within northeastern states of Nigeria in order to find out whether there is significant difference between the academic performances of the two entrants. A total of 250 academic performance records (Cumulative Grade Point Average) of students were sampled and 250 questionnaires were distributed among the stakeholders across five polytechnics in Bauchi, Borno and Yobe states to answer the research questions. Both descriptive and inferential statistical tools were used for the data analysis. The Findings revealed that there is no significant difference in the academic performances of "Pre-ND entrants" and "UMTE entrants" on the basis of Student's T- Test as the justification of this claim is apparent from the fact that p-value (0.011) turned out to be less than the significance level at five percent. Conclusively, there is no cause of alarm with regard to the order of the National Board for Technical Education which abolishes the Pre-ND programme since no significant difference was observed in the means of the performance records and the fact that Cumulative Grade Point Average is the yardstick for measuring academic performance of students.
\end{abstract}

Keyw ords: Academic performance, polytechnic, Pre-ND, UTME

\section{Introduction}

In a bid to turnout the middle-level manpower needed for industrial and technological development of the country, The Federal Polytechnic Statue enacted Decree No. 33 of 1979 as amended by Decree No. 5 of 1993, to give legal basis for the establishment of Federal Polytechnics in Nigeria(Madukairo, 2011). According to the National Board for Technical Education, a polytechnic is a technical institution offering post-secondary technical education programmes leading to the award of diplomas/ certificates such as the National Diploma (ND) and Higher National Diploma (HND)

The Decree mandated each Polytechnic with the following functions: (a) to provide full-time or part-time courses of instruction and training- (i) in technology, applied science, commerce and management; and (ii) in such other fields of applied learning relevant to the needs of the development of Nigeria in the area of industrial and agricultural production and distribution and for research in the development and adaptation of techniques as the Council may from time to time determine; (b) to arrange conferences, seminars and study groups relative to the fields of learning specified above; and (c) to perform such other functions as in the opinion of the Council may serve to promote the objectives of the polytechnic. However, the attainment of the minimum required credit passes that include English Language and Mathematics in the Senior School Certificate Examination (SSCE) and minimum cut off point in the Joint Admission Matriculation Board (JAMB) entrance examination (Unified Tertiary Matriculation Examination (UTME)) for admission into the polytechnics' programme is a turning point for greater proportion of candidates and this constituted low level enrollment into the polytechnics among other reasons. Part of this view is consistent with the opinion that it has become increasingly common to find youths who have written their Senior Secondary Certificate Examination (SSCE), conducted by the West African Examination Council (WAEC) but could neither fit into the tertiary institutions of learning nor the labor market in Nigeria because their academic achievement (performance in the SSCE) was poor as noted by(Kpolovie, Joe, \& Okoto, 2014). The Pre - National Diploma (Pre- ND) was introduced to overcome this challenge in the polytechnics. Hence, the Programme is a product of circumstances initiated to produce qualified candidates for admission into the National Diploma (ND) Programmes offered in the Polytechnics for those candidates that could not attain the minimum requirement for 
admission into Polytechnics' National Diploma programmes. The structure of the Programme consists of formal lectures and practical work in the relevant subjects and one or more vocational course(s) module(s) relevant to the various programmes under each cluster(Federal polytechnic Damaturu, 2012).Within the context of this study, "UTME Entrants" and "Pre-ND Entrants" are students admitted into National Diploma Programme through the UTME and Pre-ND programme conducted by JAMB and the selected Polytechnics respectively.

\subsection{Statement of the Problem}

(Olatunde \& Abatcha, 2014)concluded that the performance of the Pre-ND entrants was better compared to the JAMB entrants in a paper titled "Comparative Analysis of the Impact of Pre-ND Programme on the Performance of Pre-ND and Jamb Entrants", presented at the $5^{\text {th }}$ National Conference of ASUP Nasarawa State Polytechnic, Lafia.Their investigation was based on frequency counts of placement of the entrants after one year. But the likes of(Kpolovie et al., 2014) is of the opinion that academic achievement is a yard stick for ascertaining the capabilities of a student from which his overt, covert and inherent or unrevealed abilities could be inferred. In addition,(Kedah \& Ali, 2009)noted that students' academic achievement is measured by the Cumulative Grade Point Average (CGPA). Therefore, it may not be misleading to argue that the findings in(Olatunde \& Abatcha, 2014)need to be supported with investigation based on academic performance.

With the findings of this study, the impact of the "Pre - ND" Programme on academic performance of National Diploma Programme students could be evaluated and the relevance or otherwise of the programme could be justified.

\subsection{Aim and Objectives of the Study}

This study is aimed at evaluating the impact of Pre- ND Programme on academic performance of National Diploma Programme students of polytechnics with the objectives of:

- Determining whether there is significant difference in the academic performance of "UTME entrants" and "Pre-ND entrants".

- Conducting a test of independence on the impact of Pre-ND programme on academic performance between "UTME entrants" and "Pre-ND entrants".

- Determining the relevance or otherwise of the Pre-National Diploma Programme.

\subsection{Significance of the Study}

This research becomes necessary as the outcomes could be used as a guide to the Polytechnic administrators, planners and more importantly to the government and policy makers to be able to identify the impact and relevance or otherwise of the Pre-National Diploma Programme in the Polytechnics.

\subsection{Scope of the Study}

This research work is limited to the comparative analysis of the impact of Pre - National Diploma Programme on academic performance of National Diploma Programmes students of polytechnics in Bauchi, Borno and Yobe States using Student's t- test and Chi-square test of independence.

\subsection{Research Questions}

- Is the academic performance of "Pre-ND entrants" better than that of the "UTME entrants" of the National Diploma Programmes of Polytechnics?

- Does the academic performance of students is influenced by the mode of entry into the National Diploma Programmes of Polytechnics?

\subsection{Research Hypotheses}

- $\mathrm{H}_{01}$ : The academic performance of "Pre-ND entrants" is better than that of the "UTME entrants" of National Diploma Programmes of Polytechnics.

- $\mathrm{H}_{02}$ : There is significant difference in the academic performance of "UTME entrants" and "Pre-ND entrants" of National Diploma Programmes of Polytechnics.

\section{Review of Related Literature}

Many undertakings are readily available on the impact or otherwise of foundation programme on the academic performances of students of tertiary institutions. This claim is justifiable to some extent based on opinions of authors like(Kedah \& Ali, 2009)who believe thatmany studies have been developed concerning the factors that influence students' performance. Similarly,(Amasuomo, 2014) is of the opinion that various studies have been carried out on the factors that affect students' academic performance or achievement in schools, colleges and universities. On a specific note, he opined that entry qualifications, which are the results of prior or previous academic performance likely to affect the students' future academic performance. This is in line with the findings of(Emmanuel \& Timothy, 2012) who reported that entrants by Direct Entry (equivalence of Pre-ND Entrants in the Polytechnics) had better performance in Bachelor of Science Mathematics Education than their UTME counterparts in their paper titled "Comparison of the Academic Performances of Students Admitted Through University Matriculation Examination and Direct Entry Modes". In a related paper(Olatunde \& Abatcha, 2014)concluded that the performance of the 'Pre-ND' entrants was better compared to the JAMB entrants. Their investigation was based on frequency counts of placement of the entrants after one year. But the likes of(Kpolovie et al., 2014) is of the opinion that academic achievement is a yard stick for ascertaining the capabilities of 
a student from which his overt, covert and inherent or unrevealed abilities could be inferred. In addition,(Kedah \& Ali, 2009)noted that students' academic achievement is measured by the Cumulative Grade Point Average (CGPA). Therefore, it may not be misleading to argue that the findings in(Olatunde \& Abatcha, 2014)need to be supported with investigation based on academic performance.

\section{Methodology}

Both survey design and documentary method were adopted in order to answer the research questions. The population of this study comprises all the students of the five Polytechnics in Bauchi, Borno and Yobe States of Nigeria where the mode of entry into the National Diploma Programme is open to both "Pre-ND Entrants" and "UTME Entrants". The sampling method considered was cluster sampling, where each polytechnic was sub-divided into schools/ faculties, then a random selection was made among the schools/faculties and this was followed by a final selection of one department within the selected school/ faculty to represent the polytechnic. Additionally, the sampling units were the final Cumulative Grade Point Average(CGPA) of National Diploma Programme students of 2012/ 2013 session and the relevant stakeholders (Lecturers) of the Polytechnics in Bauchi, Borno and Yobe States of Nigeria.

\subsection{Data Analysis}

In order to answer the research questions, both descriptive and inferential statistical tools were employed in the data analysis by using the Statistical Package for the Social Sciences (SPSS) and Minitab. The two research hypotheses were tested at $5 \%$ level of significance using Independent Student'st - test and Chi-square test of independence.

\section{Results}

The results of the descriptive analysis of the data and that of the tests of the two hypotheses are presented in table $1-3$.

\subsection{Research Question One}

- Is the academic performance of "Pre-ND entrants" better than that of the "UTME entrants" of the National Diploma Programmes of Polytechnics?

To answer this question, data were analysed using Student T-test, Mean and Simple Bar Chart of Students' CGPA as shown in table 1 and 2; figure 1 and 2.

\begin{tabular}{|c|c|c|c|c|c|c|c|}
\hline Mode of Entry & Mean & $\mathbf{N}$ & Std. Deviation & Std. Error Mean & \multicolumn{3}{|c|}{ T-test } \\
\cline { 6 - 8 } & & & & & Df & T & Sign. \\
\hline Pre - ND & 2.640640 & 125 & .5506547 & .0492521 & 124 & 2.567 & 0.011 \\
\hline UTME & 2.482560 & 125 & .5799943 & .0518763 & & & \\
\hline
\end{tabular}

Table 1: Descriptive Statistics of the Sampled Students' CGPA with Respect to Mode of Entry

From the above table, it can be seen that mean CGPA of Pre-ND entrants is approximately 2.64 while that of Direct entrants is 2.48. Similarly, from figure 1 below it is clearly apparent that there is no significant difference between the mean CGPA of the two groups and this is in line with the result of the $t$-test where $t_{\text {cal }}$ is equal to 2.567 which is greater than the $t_{\text {tab }}\left(t_{124,0.05}=1.64\right)$. This is contrary to the opinions of the respondents where $66.8 \%, 21.6 \%$ and $11.6 \%$ answered Yes, No and Same respectively on the said question.

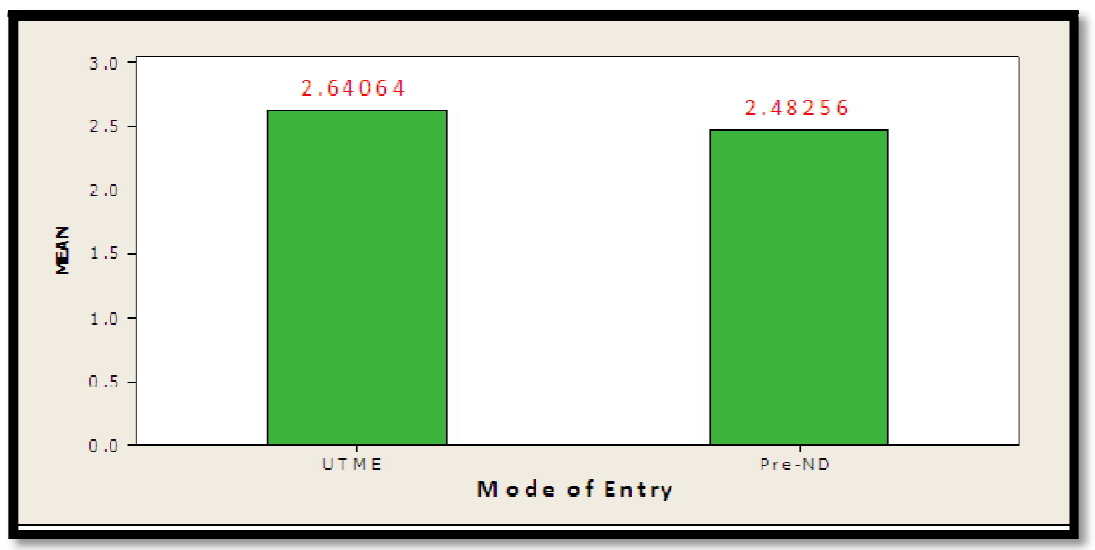

Figure 1: Simple Bar Chart Of the Means of the CGPA of the Two Entrants

\subsection{Research Question Two}

- Does the academic performance of students is influenced by the mode of entry into the National Diploma Programmes of Polytechnics?

To answer this question, data were analysed using frequency counts and Chi-square test of independence as shown in table 3 and 4 respectively. 


\begin{tabular}{|c|c|c|c|c|c|}
\hline \multirow{2}{*}{ Mode of Entry } & \multicolumn{5}{|c|}{ Class of Diploma } \\
\cline { 2 - 6 } & Distinction & Upper Credit & Lower Credit & Pass & Total \\
\hline Pre-ND & 4 & 38 & 66 & 17 & 125 \\
\hline UTME & 4 & 26 & 70 & 25 & 125 \\
\hline Total & 8 & 64 & 136 & 42 & 250 \\
\hline
\end{tabular}

Table 2: Frequency Counts of the Sampled Students'

CGPA with Respect to Class of Diploma

Table 2 above shows that each of the two entry mode had 4 distinction National Diploma graduates. While in the upper credit division, the Pre-ND entrants outperformed the direct entrants but the opposite is the case in the lower credit division.

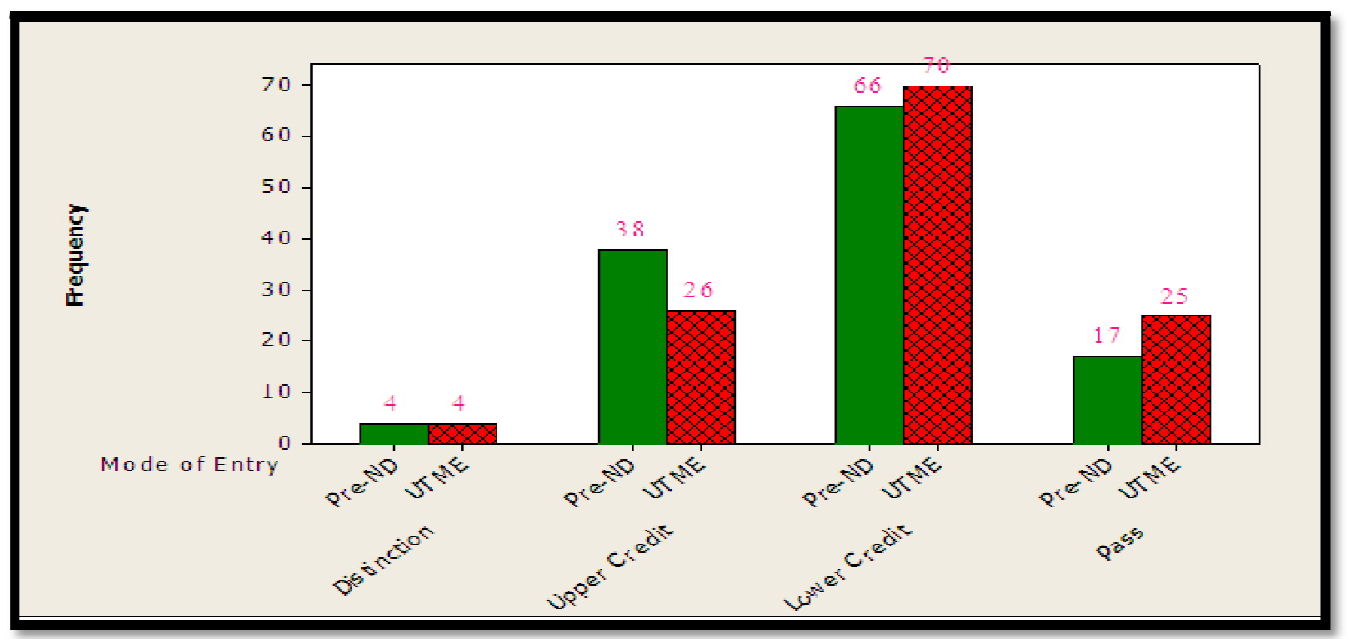

Figure 2: Multiple Bar Chart of Frequency Distribution of the CGPA of the Two Entrants

\begin{tabular}{|c|c|c|c|c|c|c|}
\hline \multirow{2}{*}{$\begin{array}{l}\text { Mode of } \\
\text { Entry }\end{array}$} & \multicolumn{4}{|c|}{ Class of Diploma } & \multirow[t]{2}{*}{ Total } & \multirow{2}{*}{$\begin{array}{c}\text { P-Value/ } \\
\chi^{2}\end{array}$} \\
\hline & Distinction & $\begin{array}{l}\text { Upper } \\
\text { Credit }\end{array}$ & $\begin{array}{l}\text { Lower } \\
\text { Credit }\end{array}$ & Pass & & \\
\hline Pre-ND & $4(4)$ & $38(32)$ & $66(68)$ & $17(21)$ & 125 & \multirow{3}{*}{$\begin{array}{c}0.273 / \\
3.891\end{array}$} \\
\hline UTME & $4(4)$ & $26(32)$ & $70(68)$ & $25(21)$ & 125 & \\
\hline Total & 8 & 64 & 136 & 42 & 250 & \\
\hline
\end{tabular}

Table 3: Chi-Square Analysis of the Sampled Students' CGPA with Respect to Class of Diploma

Results in table 3 indicated that academic performance of "Pre-ND entrants" is better than that of the "UTME entrants" of the National Diploma Programmes of Polytechnics since p-value is greater than the level of significance at five per cent.

\subsubsection{Hypothesis One}

- $\mathrm{H}_{01}$ : There is significant difference in the academic performance of "UTME entrants" and "Pre-ND entrants" of National Diploma Programmes of Polytechnics.

The hypothesis was tested using $\mathrm{T}$ - test, the result indicated that calculated $\mathrm{T}\left(\mathrm{t}_{\mathrm{cal}}=2.567\right)$ is greater than the tabulated $\mathrm{T}$ $\left(\mathrm{t}_{124,0.05}=1.64\right)$ at 124 degrees of freedom and 0.05 level of significance. Therefore the null hypothesis is rejected and this implies that there is no significant difference in the academic performance of "UTME entrants" and "Pre-ND entrants" of National Diploma Programmes of Polytechnics.

\subsubsection{Hypothesis Two}

- $\mathrm{H}_{02}$ : The academic performance of "Pre-ND entrants" is better than that of the "UTME entrants" of National Diploma Programmes of Polytechnics.

The hypothesis was tested using Chi -square test of independence. The result indicated that calculated $\chi^{2}\left(\chi^{2}\right.$ cal $=$ $3.891)$ is less than the tabulated $\chi^{2}\left(\chi^{2} 3,0.05=7.81\right)$ at 3 degrees of freedom and 0.05 level of significance, thus the null hypothesis is accepted.

\section{Discussion}

The result of this study revealed that there is no significant difference in the academic performance of "Pre-ND entrants" and "UTME entrants" of National Diploma Programmes of Polytechnics. This implies academic performance of "Pre-ND entrants" is not better than that of the "UTME entrants" of the National Diploma Programmes. This claim is

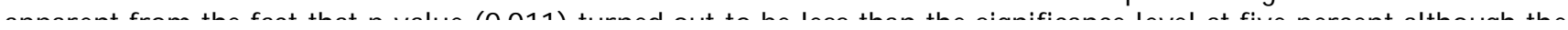


mean CGPA of the Pre-ND entrants is slightly higher than that of UTME entrants as shown in table 1.Conversely, the result of the Chi-square test of independence (table 3) revealed that academic performance of "Pre-ND entrants" is better than that of the "UTME entrants" of the National Diploma Programmes since p-value (0.273) is greater than the level of significance (five per cent). This result reflectedthe opinions of the respondents, where $66.8 \%, 21.6 \%$ and $11.6 \%$ answered Yes, No and Same respectively to the question: Is the average academic performance of "Pre-ND entrants" better than that of the "UTME entrants" of National Diploma Programmes of Polytechnics'?These results are consistent with the of findings of (Emmanuel \& Timothy, 2012)as the authorsdiscovered that entrants by Direct Entry (equivalence of Pre-ND entrants in the Polytechnics) had better performance in Bachelor of Science Mathematics Education than their UTME counterparts. Nevertheless, the slight difference observed in the mean CGPA is in accordance with the conclusion that the performance of the Pre-ND entrants was better compared to the JAMB entrants reported by (Olatunde \& Abatcha, 2014) in their paper titled "Comparative Analysis of the Impact of Pre-ND Programme on the Performance of Pre-ND and Jamb Entrants".It may not bemisleading to infer thatthe difference in the mean CGPAcould be attributed to earlier acquaintanceof the Pre-ND entrants to tertiary education and basic courses coupled with their desire for achievement in order to overcome the challenges that hinders their quest to secure admission through the UTMEand this is in line with the study of (Kogut, 1993)) who noted that academic performance is directly proportional to maturation. That is, the higher the maturity, the higher the performance as cited by (Emmanuel \& Timothy, 2012)

\section{Conclusion}

Based on the findings and the fact that the Cumulative Grade Point Average (CGPA) is the yardstick for measuring academic performance of students, it can be concluded that there is no significant difference in the average academic performance of "Direct entrants" and "Pre-ND entrants" of Nigerian Polytechnics' National Diploma Programmes. Consequently, the abolition of the Pre-ND Programme is justifiable to some extent.

\section{Recommendation}

Based on the findings and the conclusion, the National Board for Technical Education should organize sensitization/ interactive workshop in order enlightens, listen and address anxiety of the stakeholders in the Polytechnics on the new directives that abolishes the Pre-ND Programme.

\section{References}

i. Amasuomo, M. J. O. (2014). Academic performance of students admitted with different entry certificates to the Nigerian Certificate In Education Programme at the Federal College of Education (TECHNICAL), Omoku. Journal of Technology and Science Education (JOTSE), 39-47.

ii. Emmanuel, K., \& Timothy, F. (2012). Comparison of the Academic Performances of Students Admitted Through University Matriculation Examination and Direct Entry Modes. Journal of Science and Science Education, 3(1), 6777.

iii. Federal polytechnic Damaturu. (2012). Students' Information Handbook 2012.

iv. Kedah, M., \& Ali, N. (2009). The Factors Influencing Students ' Performance at Universiti Teknologi MARA Kedah , Malaysia, (July 2014).

v. Kogut, L. S. (1993). No TitleA General Course for Science and Engineering Majors with Marginal Academic Preparation. Journal of Chemical Education X, 70(7), 565-567.

vi. Kpolovie, P. J., Joe, A. I., \& Okoto, T. (2014). Academic Achievement Prediction : Role of Interest in Learning and Attitude towards School, 1(11), 73-100.

vii. Madukairo, E. (2011). Revitalizing Polytechnics Education in Nigeria. Retrieved October 20, 2014, from http:/ / nigeriancommentaries.blogspot.com/2011/ 03/ revitalizing-polytechnics-education-in.html

viii. Olatunde, B. Z, \& Abatcha, A. B. (2014). Comparative Analysis of the Impact of "Pre-ND" Programme on the Performance of "Pre-ND" and "Jamb" Entrants. In 5th National Conference of ASUP Nasarawa State Polytechnic. Lafia. 